\title{
Acid-sensing ion channels: trafficking and synaptic function
}

\author{
Xiang-ming Zha
}

\begin{abstract}
Extracellular acidification occurs in the brain with elevated neural activity, increased metabolism, and neuronal injury. This reduction in $\mathrm{pH}$ can have profound effects on brain function because $\mathrm{pH}$ regulates essentially every single biochemical reaction. Therefore, it is not surprising to see that Nature evolves a family of proteins, the acid-sensing ion channels (ASICS), to sense extracellular pH reduction. ASICs are proton-gated cation channels that are mainly expressed in the nervous system. In recent years, a growing body of literature has shown that acidosis, through activating ASICs, contributes to multiple diseases, including ischemia, multiple sclerosis, and seizures. In addition, ASICs play a key role in fear and anxiety related psychiatric disorders. Several recent reviews have summarized the importance and therapeutic potential of ASICs in neurological diseases, as well as the structure-function relationship of ASICS. However, there is little focused coverage on either the basic biology of ASICs or their contribution to neural plasticity. This review will center on these topics, with an emphasis on the synaptic role of ASICs and molecular mechanisms regulating the spatial distribution and function of these ion channels.
\end{abstract}

Keywords: Acid-sensing ion channel (ASIC), Acidosis, Calcium, Dendritic spine, Glycosylation, Signaling, Synapse, Trafficking

\section{Introduction}

Acid-sensing ion channels (ASICs) are a family of proton-gated cation channels which are expressed primarily in the nervous system [1,2]. ASICs belong to a superfamily which also contains degenerins (DEG) and epithelial sodium channels $(\mathrm{ENaC})$. All members within the ENaC/DEG/ASIC (EDA) superfamily share the same topology, with the $\mathrm{N}$ - and C-termini located inside the cell and a large well organized, cysteine-rich extracellular domain $[1,2]$. There are four genes encoding at least six different ASICs (Table 1). ASICs function as trimers $[3,4]$ and conduct mostly $\mathrm{Na}^{+}$. Homomeric ASIC1a and human ASIC1b, as well as ASIC1a/2b heteromers, also have a low permeability to $\mathrm{Ca}^{2+}$ [5-9]. Interestingly, at pH 7.25 (but not at pH 5.5), a complex between a truncated chick ASIC1 and Psalmotoxin (PcTx1) is nonselective to monovalent cations [10]. This result indicates that ion selectivity of ASICs can be altered under

Correspondence: zha@southalabama.edu

Department of Cell Biology and Neuroscience, College of Medicine,

University of South Alabama, 307 University Blvd, MSB1201, Mobile, AL 36688, USA

specific conditions. ASIC1 and ASIC3 start to open at about $\mathrm{pH} 7$ and 7.2, respectively, which enables them to sense $\mathrm{pH}$ changes within physiological $\mathrm{pH}$ ranges [5,11-15]. In addition, a recent study shows that human ASIC3 can also respond to alkanization [16]. Since extracellular $\mathrm{pH}$ fluctuation is common in pathological conditions, it is conceivable that ASICs play important roles in a wide spectrum of neurological diseases. Consistent with this speculation, ASICs contribute to pain, brain ischemia, multiple sclerosis, seizures as well as anxiety-related disorders $[1,2,17,18]$. These findings highlight the potential therapeutic value of targeting ASICs in diseases. In addition, recent studies reveal that ASICs and acidosis regulate dendritic spines, the site of most excitatory neurotransmission in the brain [19-21]. These data suggest that ASICs also play an important role in regulating neural plasticity in pathological conditions.

\section{Recent advances in ASIC pharmacology}

Although the canonical ligand for ASICs is protons, the massive extracellular domain of ASICs has led to the speculation that these receptors may also respond to 
Table 1 Basic channel properties, activators and inhibitors of ASICs

\begin{tabular}{|c|c|c|c|c|c|c|}
\hline Gene & Protein & $\mathrm{pH}_{50}$ & Agonist $\left(\mathrm{EC}_{50}\right)$ & Antagonist $\left(\mathrm{IC}_{50}\right)$ & lons passed & References \\
\hline \multirow[t]{5}{*}{ ASIC1(ACCN2) } & ASIC1a & $6.2-6.8$ & MitTx (9.4 nM) & $\operatorname{PcTx1}(\sim 1 \mathrm{nM})$ & $\mathrm{Na}^{+}>\mathrm{Ca}^{2+}$ & {$[5,12,13,22-27]$} \\
\hline & & & & Mambalgin (55 nM) & & \\
\hline & & & & Sevanol (2.2 mM) & & \\
\hline & & & & A-317567 $(2 \mu \mathrm{M})$ & & \\
\hline & ASIC1b & $\begin{array}{l}\sim 6.0 \text { (mouse) } \\
\sim 6.2 \text { (human) }\end{array}$ & MitTx (23 nM) & Mambalgin (192 nM) & $\begin{array}{l}\text { mouse: } \mathrm{Na}^{+} \\
\text {human: } \mathrm{Na}^{+}>\mathrm{Ca}^{2+}\end{array}$ & {$[6,7,12,13,22,24,28]$} \\
\hline \multirow[t]{2}{*}{ ASIC2 (ACCN1) } & ASIC2a & $4.5-4.9$ & Minimal activa-tion by MitTx & A-317567 $(29 \mu \mathrm{M})$ & $\mathrm{Na}^{+}$ & {$[12,15,22,25,29-31]$} \\
\hline & ASIC2b & $\mathrm{N} / \mathrm{A}$ & & & - & [29-31] \\
\hline \multirow[t]{3}{*}{ ASIC3 } & ASIC3 & $\sim 6.6$ & GMQ (0.35 mM) & APET×2 (63 nM) & $\mathrm{Na}^{+}$ & {$[13,22,25,32-36]$} \\
\hline & & & MitTx (830 nM) & Sevanol (0.35 mM) & & \\
\hline & & & & A-317567 $(9.5 \mu \mathrm{M})$ & & \\
\hline ASIC4 & ASIC4 & N/A & & & - & [37] \\
\hline \multirow[t]{8}{*}{ Heteromeric channels } & $1 a+1 b$ & 6.0 & & Mambalgin (72 nM) & $\mathrm{Na}^{+}$ & {$[15]$} \\
\hline & $1 a+2 a$ & $5.5-6.1$ & & Mambalgin (246 nM) & $\mathrm{Na}^{+}$ & {$[12,15,24,26]$} \\
\hline & $1 a+2 b$ & Same as ASIC1a & & $\begin{array}{l}\text { Mambalgin (61 nM) } \\
\text { PcTx1 ( 3 nM) }\end{array}$ & $\mathrm{Na}^{+}>\mathrm{Ca}^{2+}$ & {$[9,15,24]$} \\
\hline & $1 a+3$ & $6.3-6,6$ & & & $\mathrm{Na}^{+}$ & {$[12,15]$} \\
\hline & $1 b+3$ & 6.0 & & & $\mathrm{Na}^{+}$ & [15] \\
\hline & $1 b+2 a$ & 4.9 & & & $\mathrm{Na}^{+}$ & [15] \\
\hline & $2 a+3$ & $5.7-6.1$ & & & $\mathrm{Na}^{+}$ & {$[12,15]$} \\
\hline & $2 b+3$ & 6.5 & & APETx2 (117 nM) & $\mathrm{Na}^{+}$ & {$[15,33,36]$} \\
\hline
\end{tabular}

Note: amiloride is not included in the table because it functions as a universal blocker for ASICs and many other ion channels, such as ENaCs and sodium/ hydrogen exchangers.

other ligands [38]. Supporting this speculation, ASIC channels are potentiated by FMRFmide like peptides, dynorphin A and big dynorphin; all reduce the steadystate desensitization of ASICs [39-41]. In addition, spermine, a polyamine that is released in injury conditions, also potentiates ASIC currents by reducing the steady-state desensitization $[11,42]$. These studies, along with the link between ASICs and multiple diseases, have inspired the screening for novel ASIC ligands/antagonists using various approaches. The first non-proton ligand identified is 2-guanidine-4-methylquinazoline (GMQ), which activates ASIC3 at normal pH [32]. In addition, Bohlen et al. recently isolated a peptide, MitTx, from the venom of Texas coral snake [22]. At neutral $\mathrm{pH}$, MitTx induces sustained opening of ASICs, and is highly selective to ASIC1 (see Table 1). These findings not only provide novel tools for studying ASIC function but also suggest that physiological ligands other than protons exist.

Various ASIC inhibitors have also been isolated from venoms. PcTx1, a toxin isolated from the venom of tarantula spider, is specific to ASIC1a homomeric and ASIC1a/2b heteromeric channels $[9,23]$. APETx2, on the other hand, inhibits ASIC3 containing channels [33]. Recently, another class of peptides, named mambalgins, were isolated from black mamba venom; mambalgins inhibit several ASICs and abolish pain sensation [24]. Besides these peptides, several small molecules also inhibit ASICs. One commonly used small molecule inhibitor is amiloride. Though unspecific, amiloride has the advantage in that it has been used clinically for decades. A-317567 is a synthetic compound which inhibits ASIC1a, 2a and 3 [25]. Sevanol, or epiphyllic acid 9, 10diisocitryl ester, isolated from a plant, Thymus armeniacus, inhibits both ASIC3 and ASIC1a, with no effect on other ASIC subunits [34]. A summary of these ASIC activators and inhibitors is presented in Table 1. These reagents are useful for manipulating ASIC activities in functional studies. However, the development of additional subunit-specific pharmacological inhibitors will be valuable for targeting of ASICs in diseases.

\section{Expression and subcellular localization of ASICs Overall expression of ASICs}

The distribution of ASIC mRNA is wide spread at both peripheral and central nervous systems (PNS and CNS). The PNS expresses all ASIC subunits [5,7,29-31,35,43]. The CNS, on the other hand, primarily expresses ASIC1a, ASIC2a, and ASIC2b [29-31,35]. Almost all neurons possess robust acid-evoked ASIC type current [44-47]. Other than neurons, NG2 glia cells [48], some receptor cells [49-52], vascular smooth muscle [53], and 
immune cells [54] also express ASICs, though typically at lower levels. In addition, many types of brain tumors upregulate ASIC expression [55,56], which suggests a possible role of ASICs in tumor physiology.

Consistent with the in situ and PCR results, western blot and immunostaining detect ASIC1a protein in most brain regions. However, there are variations in the relative expression level of ASIC1a among different structures. ASIC1a levels are higher in amygdala, cingulate, periaqueductal gray, layer III of somatosensory cortex and striatum [57-59]. Within the hippocampus, the dentate gyrus region shows higher ASIC1 immunostaining than CA1 and CA3 [59]. Detailed localization of endogenous ASIC2 protein is not yet available, largely due to the lack of a reliable ASIC2 antibody for detecting endogenous ASIC2 proteins [20,52]. However, most of the currents recorded from CNS neurons show a mixed contribution from ASIC1a homomeric, ASIC1a/2a, and ASIC1a/2b heteromeric channels $[9,45,46,58,60-62]$. In addition, the properties of acid-activated current recorded suggest that the relative expression of ASIC2 varies among different brain regions. For example, currents in medium spiny neurons in striatum contain a predominant ASIC1a homomeric component [61]. Similarly, cerebellar Purkinje cells exhibit currents representative of ASIC1a homomers or $1 \mathrm{a} / 2 \mathrm{~b}$ heteromers [60]. In hippocampus, the basket cells, one class of interneuron, expresses primarily ASIC1a while many other interneurons express both ASIC1a and ASIC2 [47].

Besides the variation among brain regions and cell types, there may also be developmental changes in ASIC expression. In one study, increased maturation of the neuronal culture is associated with increased ASIC2:ASIC1a mRNA ratio and reduced inhibition of ASIC currents by PcTx1 [63], suggesting that the relative ASIC2 protein levels are increased with maturation/aging. There may also exist species differences. In cultured human cortical neurons, acid-activated currents appear to come predominantly from ASIC1a homomers [64]. In contrast, currents in mouse/rat neurons typically exhibit a higher contribution from ASIC1a/ASIC2 heteromers. This difference is interesting. However, in the human study, neurons were isolated from patients of 23-72 years old and recorded at 3-4 days in culture [64]. Most rodent studies, on the other hand, were performed on neurons obtained from embryonic or early postnatal animals and cultured for 7-21 days. Therefore, caution shall be taken as to whether the differences observed are completely attributable to species. Nevertheless, these results indicate that it will be important to study the biogenesis and function of human ASICs, preferably in human neurons.

\section{Subcellular localization of ASICs in neurons}

In peripheral neurons, ASIC1, 2, and 3 are detected in axons, axon terminals and cell bodies $[43,65,66]$. In the brain, both ASIC1a and ASIC2a show a preferential somatodendritic distribution [67-69]. In cultured CNS neurons, endogenous ASIC1a localizes primarily to dendrites with little detectable presence in axons $[19,44,70]$. Similar distribution is observed when ASIC1a and ASIC2a are expressed in organotypic hippocampal slices [19-21,71]. Of note, one previous study reports a ubiquitous distribution of ASIC1 in cultured brain neurons [57]. The reason for this discrepancy is unclear, although it is noted that the antibodies used in the above studies are different. The healthiness of the neuron also regulates ASIC localization. In spinal cord, endogenous ASIC1a is barely detectable in healthy axons, but increases drastically when the axons are injured [72]. Taken together, these data demonstrate a preferential somatodendritic targeting of ASIC1a in CNS, and suggests that altered subcellular traffficking of ASICs plays a critical role in pathological conditions.

Besides the immunostaining results, biochemical analysis shows that ASIC1a and ASIC2a are enriched in brain synaptosomes $[20,44,69]$. Together, these data suggest an increased postsynaptic trafficking of ASICs. Consistent with this speculation, ASICla shows punctate staining along the dendrites in cultured brain neurons, which indicates that ASIC1a is clustered in dendritic spines (Figure 1A). To obtain high resolution images and study ASIC localization in a more physiological environment, we transfected epitope tagged ASIC1a and ASIC2a into organotypic hippocampal slices. Both ASIC1a and ASIC2a are present in most dendritic spines in slice neurons [19-21,71]. In addition, the relative level of ASIC1a in spines is higher as compared to that of a membrane-targeted Lck-GFP, demonstrating that ASIC1a is enriched in dendritic spines (Figure 1B). These data indicate a preferential trafficking of ASIC1a and ASIC2a to the postsynaptic membrane.

Synaptic and dendritic targeting of ASIC1a is further supported by electrophysiological recordings and $\mathrm{Ca}^{2+} \mathrm{im}-$ aging experiments. Puffing acidic solutions to dendritic region elicits typical ASIC-type currents in hippocampal slice neurons [47]. In addition, using cameleon as a $\mathrm{Ca}^{2+}$ sensor, we have imaged acid-induced $\mathrm{Ca}^{2+}$ changes in hippocampal slices $[19,20]$. Acidic stimulation leads to a rapid increase of intracellular $\mathrm{Ca}^{2+}$ concentration $\left(\left[\mathrm{Ca}^{2+}\right]_{\mathrm{i}}\right)$ in dendritic spines, dendrites and cell bodies of pyramidal neurons (Figure 2A). The response is abolished in ASIC1a-/- slice neurons and reduced in ASIC2-/slice neurons. These functional results, together with the immunolocalization and biochemical data, demonstrate that endogenous ASICs are not only preferentially trafficked to dendrites and spines but also function as the postsynaptic proton receptor there. 


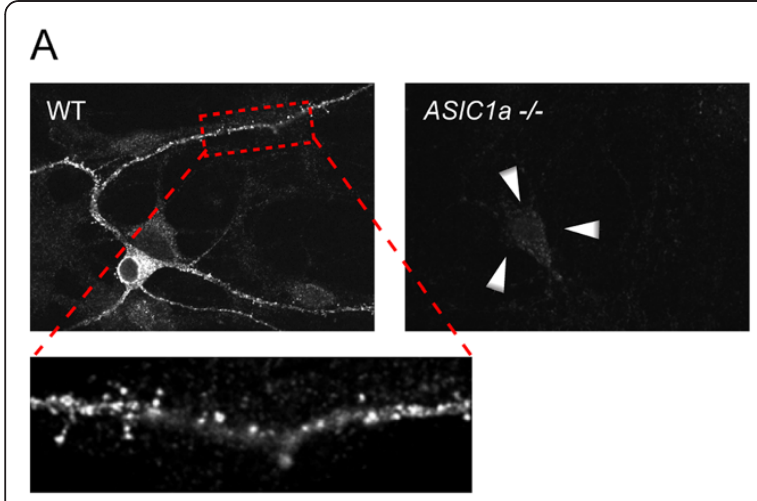

B

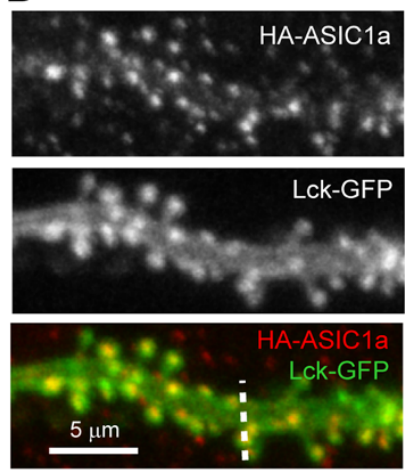

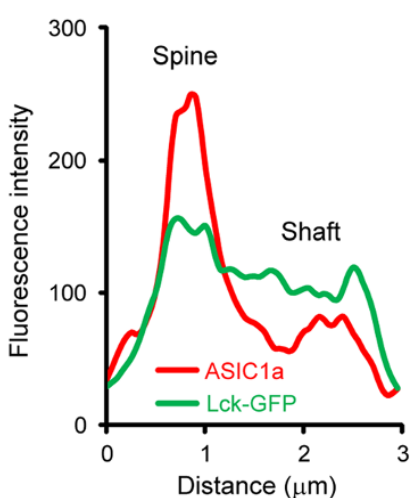

Figure 1 ASIC1a localization in dendritic spines. A) Immunofluorescence images showing the localization of endogenous ASIC1a in cultured neurons. Wild type (WT) and ASIC1a-/- cortical neurons were stained with an anti-ASIC1a antibody. Inset at the bottom shows a high magnification view of the boxed region in WT. Note the punctate staining along the dendrite, suggesting the presence of ASIC1a in dendritic spines. B) Confocal images showing the enrichment of ASIC1a in spines of slice neurons. Organotypic hippocampal slices were transfected with HA-ASICla and a membrane-targeted Lck-GFP. ASIC1a localization was detected by immunostaining with an anti-HA antibody. Plot on the right shows the relative fluorescence intensity of ASIC1a and LCk-GFP along the line drawn on the merged image. ASIC1a shows a higher relative spine:shaft signal as compared to Lck-GFP, demonstrating that ASIC1a preferentially traffics to dendritic spines. Data adapted from [19,21].

\section{ASIC and neuron physiology}

Mechanisms by which ASIC activation increases $\left[\mathrm{Ca}^{2+}\right]_{i}$

As stated above, ASIC activation mediates acidosisinduced $\left[\mathrm{Ca}^{2+}\right]_{\mathrm{i}}$ rise in neurons. Part of this $\mathrm{Ca}^{2+}$ increase is due to direct $\mathrm{Ca}^{2+}$ entry through ASIC1a containing channels [73]. However, the relative permeability of $\mathrm{Ca}^{2+}$ is low: $p \mathrm{Na}^{+} / p \mathrm{Ca}^{2+}$ is $2.5,18.5$ and 25 in three studies on ASIC1a homomers $[5,7,8]$, and $\sim 4.1$ for ASIC1a/2b heteromers [9]. Consistent with these data, several studies show that most of acidosis-induced $\left[\mathrm{Ca}^{2+}\right]_{\mathrm{i}}$ increase in neurons are likely due to secondary mechanisms. In hippocampal slices, replacing extracellular $\mathrm{Na}^{+}$with NMDG reduced acidic stimulation-induced $\left[\mathrm{Ca}^{2+}\right]_{\mathrm{i}}$ rise by $\sim 86 \%$, showing that $\mathrm{Na}^{+}$influx through ASICs is important [19]. In chick dorsal root ganglion neurons, direct $\mathrm{Ca}^{2+}$ entry through ASICs also contributes little to acid-induced $\mathrm{Ca}^{2+}$ increase [74]. Moreover, clamping the membrane potential at $-70 \mathrm{mV}$ abolishes acidosis-induced $\left[\mathrm{Ca}^{2+}\right]_{\mathrm{i}}$ increase in cortical neurons [75], and inhibiting voltage-gated $\mathrm{Ca}^{2+}$ channels (VGCCs) largely eliminates acidosis-induced $\mathrm{Ca}^{2+}$ increase [19,75].

These data suggest the following model (Figure 2B): acidosis activates ASIC channels; $\mathrm{Na}^{+}$along with a small number of $\mathrm{Ca}^{2+}$ enters the cell, which lead to membrane depolarization; then VGCCs get activated and initiate the main $\mathrm{Ca}^{2+}$ influx. This conclusion is important for understanding how ASICs impact neuron physiology. It suggests that non-calcium permeable ASIC channels, e.g., ASIC1a/2a heteromers, can make a significant contribution to acidosis-induced $\left[\mathrm{Ca}^{2+}\right]_{\mathrm{i}}$ responses. Supporting
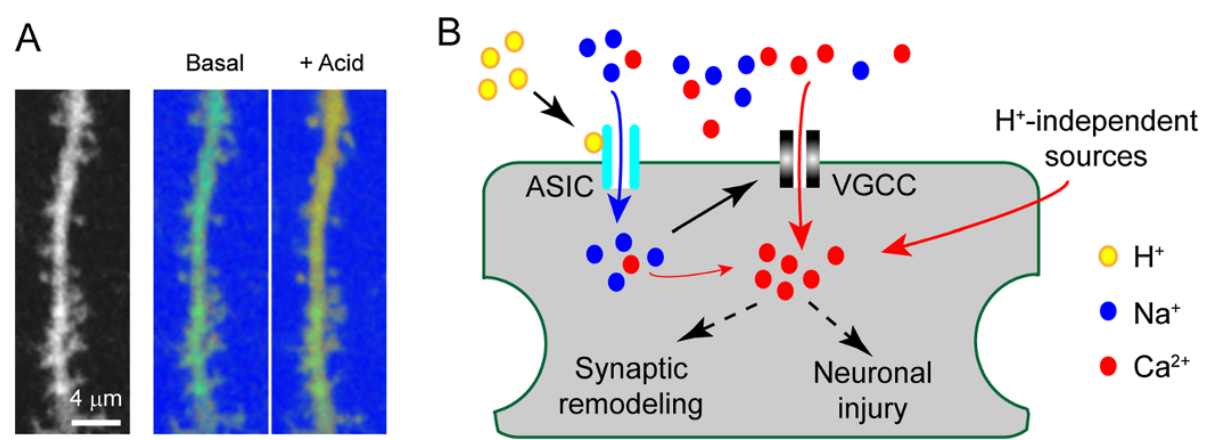

Figure 2 Mechanisms by which protons increase $\left[\mathrm{Ca}^{2+}\right]_{i}$. A) $\mathrm{Ca}^{2+}$ imaging showing acidosis-induced $\left[\mathrm{Ca}^{2+}\right]_{\mathrm{i}}$ increase in dendrites and dendritic spines. Organotypic hippocampal slices were transfected with cameleon and stimulated with a pH 6.0 solution. Left image shows the overview of the imaged dendritic segment. Right ratiometric images show YFP/CFP ratio (red indicates high while blue indicates low $\mathrm{Ca}^{2+}$ ) before and during acidic stimulation. Note the increase in $\mathrm{Ca}^{2+}$ in the dendrite and most dendritic spines. Data adapted from [20]. B) Drawing showing how protons lead to $\left[\mathrm{Ca}^{2+}\right]_{i}$ increase in neurons. See text for detailed explanation. Depending on the magnitude and duration of the $\mathrm{Ca}^{2+}$ rise, acidosis can alter neural plasticity or, when $\left[\mathrm{Ca}^{2+}\right]_{i}$ passes certain threshold level, lead to neuronal injury. 
this conclusion, deleting the ASIC2 gene, which takes away both $\mathrm{ASIC} 1 \mathrm{a} / 2 \mathrm{a}$ and $\mathrm{ASIC1} 1 \mathrm{a} / 2 \mathrm{~b}$ heteromers, significantly reduces acidosis-induced $\mathrm{Ca}^{2+}$ rise [20]. This model also argues that when considering the effect of acidosis, the number of functional ASIC channels is important as opposed to the number of " $\mathrm{Ca}^{2+}$-conducting" populations.

Other downstream molecules are also involved in response to acidosis and ASIC activation. Besides VGCCs, store-operated release and sigma receptors also contribute to $\mathrm{H}^{+}$-induced $\left[\mathrm{Ca}^{2+}\right]_{\mathrm{i}}$ increase in hippocampal slice neurons and dissociated cortical neurons, respectively $[19,75]$. CaMKII phosphorylation is also affected by altered ASIC1a expression. Brains isolated from ASIC1a null mice show a reduced CaMKII phosphorylation while those from the transgenic mice overexpressing ASIC1a have increased CaMKII phosphorylation [19]. This result suggests that manipulating ASIC1a expression level, and presumably ASIC activity, is sufficient to regulate $\mathrm{Ca}^{2+}$ signaling in vivo. How ASICs get activated in physiological conditions remains unclear. However, with functional magnetic resonance imaging, one recent report shows that learning induces acidification in human brain [76]. Although the exact magnitude of $\mathrm{pH}$ reduction in this paradigm remains to be determined, this study provides a direct support for potential ASIC activation by protons in physiological conditions.

\section{ASIC and synaptic function}

Their presence in dendritic spines suggests that ASICs regulate synaptic physiology. Several studies have tested this hypothesis in various systems. In hippocampal neurons, deleting the ASICla gene has no effect on basal levels of GABA, AMPA and NMDA currents [44,77]. However, ASIC1a deletion decreases the ratio of AMPA: NMDA currents in microisland hippocampal cultures [77]. Also in the microisland culture system, deleting the ASIC1a gene reduces paired-pulse responses. This result is consistent with a reduced long term potentiation in the ASIC1a knockout [44], and suggests that activation of ASICs contributes to increased synaptic efficacy in these conditions. One intriguing finding is that deleting the ASIC1a gene or inhibiting ASIC1a increases the frequency of miniature excitatory postsynaptic potentials in the microisland cultured neurons [77]. The mechanism for this observation remains unclear, but may indicate a possible feedback regulation as a consequence of reduced ASIC activity.

The exact role of ASIC1a at synapses may also depend on the experimental system studied. In contrast to the results in slices and cultured hippocampal neurons, inhibiting ASIC1a or silencing ASIC1a with siRNA in retina reduces photopic (cone-mediated) electroretinogram (ERG), but had little effect on scotopic (rod-mediated) ERG [78]. Deleting the ASIC2 gene, on the other hand, increases scotopic ERG in response to mid- to highintensity light, but has no effect on photopic ERG [52]. Despite the differential contribution of ASIC1a and ASIC2 in the rod and cone pathways, ASIC activation in both cases appears to be inhibitory on neurotransmission.

These electrophysiological findings are consistent with the synaptic localization of ASICs, and indicate that ASIC activation affects synaptic physiology. One pivotal question here is what is the contribution of ASICs to synaptic transmission, either in physiological or pathophysiological conditions. However, attempts to record an ASIC-initiated current during synaptic transmission have been unsuccessful [57]. This could be due to technical reasons. For example, $\mathrm{H}^{+}$are buffered fast, which may impose difficulty for detecting small ASIC-generated synaptic currents when record at the cell body. The rapid desensitization of ASICs also adds technical challenges for detecting an ASIC specific contribution. Interestingly, one recent study shows that high frequency acidic stimulation can abolish the desensitization of ASIC1a, suggesting prolonged ASIC activation under similar conditions [79]. This result raises the possibility that, with further tweaking of the experimental protocol, along with the novel tools recently developed (e.g. the specific pharmacological reagents), one may uncover a specific contribution of ASICs to neurotransmission.

\section{ASICs, acidosis and spine remodeling}

In addition to the effects on synaptic physiology, ASICs also regulate structural remodeling of synaptic sites. In hippocampal slice neurons, both transient and chronic overexpression of human ASIC1a increases the number and length of dendritic spines [19]. Conversely, knockdown of ASICla with siRNA or expressing a dominant-negative ASIC1a construct reduces spine numbers. Deleting the ASIC2 gene, which decreases synaptic targeting of ASIC1a, reduces the density of spine synapses [20]. These results show a good correlation between ASIC1a expression/synaptic levels and spine density. However, deleting the ASIC1a gene has no significant effect on dendritic spines [19]. The reason for this result is unclear. One possible, though not easy to test, explanation is that developmental compensation in the chronic knockout model leads to the lack of an effect in ASIC1a null slices. Another somewhat controversial finding is that overexpressing a mouse ASIC1a has no significant effect on spine number or length [21], which contrasts with the increased spine density observed with human ASIC1a overexpression. It is possible that the intrinsic difference between human and mouse ASIC1a is the cause. Supporting this speculation, human ASICla shows larger acid-activated current and is less susceptible to steady-state desensitization when compared to mouse ASIC1a [21,40]. Another possible contributing 
factor is the age of the cultures. In Jing et al. [21], slices were studied at the age equivalent to 17 days old, which is more mature than the 13 day old culture in Zha et al. [19]. In the literature, there are precedents that the effect on spines depends upon the developmental stages. One such example is A kinase anchor protein 150 (AKAP150). Disrupting the AKAP150 gene increases spine density at 2 weeks of age but this effect is not seen in adult stage [80]. Further study is needed to test these possibilities. Nevertheless, current data demonstrate that ASICs play an essential role in spine morphogenesis and/ or maintenance.

The results above further suggest that acidosis, through activating ASICs, regulates spines/synapses. Indeed, treating organotypic hippocampal slices with a $\mathrm{pH}$ 6 buffer reduces the density and length of dendritic spines in a time-dependent manner [21]. As expected, deleting the ASIC1a gene abolishes acidosis-induced spine loss. These data reveal that, in addition to the "canonical" neurotoxic effect (see next section), acidosis also modulates synaptic remodeling.

Given the fact that acidosis typically lasts for some time in diseases, the above finding suggests that acidosis contributes to the change in brain plasticity in pathological conditions. However, several important questions remain to be answered. First, in Jing et al., spine remodeling was induced by $1 \mathrm{hr}$ incubation in medium buffered at $\mathrm{pH} 6$ [21]. Although a $\mathrm{pH}$ reduction to 6.0 or even lower occurs in conditions like severe ischemia, the duration in those cases is probably shorter, about 15-30 minutes [81]. However, a pH reduction to $\sim \mathrm{pH} 6.5$ lasted for hours following middle cerebral artery occlusion (MCAO) [82]. Therefore, it is necessary to answer whether a persistent milder acidosis affects spines. It will also be interesting to reveal the effect of acute acidosis on spine dynamics. Timelapse experiments in vitro and in vivo will be valuable in addressing these questions. In addition, it will be important to ask whether acidosis contributes to spine remodeling in diseases, e.g., ischemia or seizures, which are known to reduce dendritic spines $[83,84]$. In parallel with the changes in spine morphology, it will also be important to ask what effect acidosis has on synaptic physiology, including plasticity. Answers to these questions will be pivotal for our understanding of how acidosis and ASICs regulate synaptic plasticity in diseases.

\section{ASIC activation and neuronal injury}

Through increasing $\left[\mathrm{Ca}^{2+}\right]_{\mathrm{i}}$, acidosis can lead to neuronal injury (Figure 2B). This mechanism apparently contributes to a major part of ischemia-induced neuronal death $[73,82,85,86]$. In the MCAO model of brain ischemia, deleting the ASIC1a gene reduces MCAO-induced infarct volume $[42,73,82]$. Besides ischemia, deleting
ASIC1a also slows down the disease progression in an experimental autoimmune encephalomyelitis model [54]. These data indicate that ASIC1a activation exacerbates neuronal injury in certain disease paradigms. ASIC activation can also be beneficial. For example, the activation of ASIC1a is required for attenuating seizure progression; deleting the ASIC1a gene or inhibiting ASIC1a increases seizure severity [87]. Similar mechanism may also apply to other systems. In retina, deleting the ASIC2 gene increases the susceptibility of retina neurons to bright illumination-induced damage [52]. In ASIC2-/but not wild-type retina, the outer and inner nuclear layers, ganglion cell layer, and pigmented epithelium all show increased apoptosis following a two-hour challenge with bright light.

The results on seizure and light-induced retina damage appear counterintuitive at the first sight, because ASIC activation leads to increased $\left[\mathrm{Ca}^{2+}\right]_{\mathrm{i}}$ and neuronal firing, which typically leads to excitotoxicity. However, ASICs are expressed in both excitatory and inhibitory neurons. As a matter of fact, many interneurons exhibit higher ASIC currents as compared to pyramidal neurons $[47,87,88]$. Therefore, through differential activation of excitatory or inhibitory neurons, acidosis can increase or attenuate the excitability of the whole network. This model will be an interesting one to test in future studies. However, both inhibitory and excitatory neurons show mixed expression of ASIC1a homomeric and ASIC1a/2a heteromeric channels [47], suggesting that selective pharmacological interventions to inhibit only interneurons or only pyramidal neurons will be difficult. One possible approach is to genetically delete ASICs in either inhibitory or excitatory neurons, and assess the outcome in various neurological diseases.

\section{Molecular mechanisms regulating ASIC trafficking and function ASIC1a trafficking on neuronal injury and spine remodeling} Increased ASIC1a surface trafficking or channel activity potentiates acidosis-induced neuronal death [41,42] and leads to hyperalgesia in response to mechanical stimulation [89]. These results indicate that the forward trafficking of ASICs is critical for acidosis-induced neuronal injury. Besides surface expression, trafficking to dendritic regions may also be important for acidosis-induced changes. An ASIC1a mutant with increased dendritic and surface levels potentiates acidosis-induced spine loss [21]. Conversely, an ASIC1a mutant with reduced trafficking has the opposite effect. Since both mutants affect both surface levels and dendritic targeting, it is difficult to conclude whether the effect observed is due to dendritic ASIC1a specifically. Nevertheless, these data support the speculation that dendritically targeted ASIC1a 
(as opposed to those at the cell body) mediates the effect of acidosis on spine remodeling.

The above data on ASIC trafficking are based on static images/samples before and after treatment. To better understand the mechanism, it will be important to visualize real-time movement of ASICs following interventions. For example, how do changes in neural activity affect ASIC trafficking, either to and from cell surface, or to synaptic sites? How do disease conditions, e.g., increased ROS production, regulate ASIC trafficking in live neurons? To address these questions, specific antibodies recognizing extracellular domain of ASICs are needed. Alternatively, one may introduce extracellularly tagged ASICs into neurons. However, it is important to note that, probably due to the complexity of its extracellular domain, inserting extracellular tags typically impairs the trafficking of ASICs ([90] and our own experience).

\section{$\mathrm{N}$-glycosylation regulates ASIC trafficking and function}

As one step toward understanding ASIC trafficking, recent studies have assessed the role of $\mathrm{N}$-glycosylation in ASIC biogenesis. In both heterologous cells and brain slices, surface ASIC1a contains a higher percentage of EndoH-resistant population, which indicates that their $N$-linked glycans have been further processed (or "matured") in mid-late Golgi [21,71]. Although the maturation of $\mathrm{N}$-linked glycans is not required for ASIC1a surface expression, matured ASIC1a apparently traffics preferentially to the cell surface. Tunicamycin, which inhibits the addition of $N$-linked sugars [91], reduces ASIC1a surface levels [21]. In addition, tunicamycin decreases dendritic targeting of ASIC1a in hippocampal slices, and reduces both the amplitude and desensitization rate of ASIC1a current in $\mathrm{CHO}$ cells. These data indicate that the maturation of $\mathrm{N}$-glycans on ASICs is important for their proper spatial distribution and channel function.

The number of potential $\mathrm{N}$-glycosylation sites in different ASIC subunits ranges from two to four, with ASIC1a and 2a each contains two. Both of the two potential glycosylation sites on ASIC1a and ASIC2a are glycosylated in heterologous cells [71,90,92]. Two separate studies have assessed the effect of glycosylation mutants on ASIC1a channel properties [71,90]. Mutating the Asn393 site reduces ASICla maturation and acidactivated current. One note to make is that the Asn393 site, which locates between the $\alpha 6$ and $\alpha 7$ helices in the crystal structure, is conserved in all ASICs [4]. It will be interesting to ask whether the glycosylation of this site has similar effect in other subunits. Unlike Asn393, the effect of Asn366 mutation differs between the two published studies. In an earlier study, a rat N366A mutant reduces acid-activated current in Xenopus oocytes [90].
In contrast, we found that mutating the Asn366 site in either mouse or rat ASIC1a increases surface expression and $\mathrm{pH}$-activated current in both $\mathrm{CHO}$ cells and Xenopus oocytes [71]. In our study, the mouse N366Q mutant also shows increased dendritic targeting in hippocampal slices, and when compared to WT ASIC1a, N366Q further potentiates acidosis-induced spine loss; both observations are consistent with an increased trafficking of the N366Q mutant. While the reason for the discrepancy between the two studies is not obvious, it is clear that $\mathrm{N}$-glycosylation is important for ASIC1a regulation.

These data further imply that processes controlling protein maturation through the secretory pathway play critical roles in regulating ASIC function. Consistent with this speculation, one report shows that most ASIC1a is trapped in endoplasmic reticulum (ER) but undergoes rapid membrane insertion in response to serum deprivation [68]. In addition, glycerol, a common reagent that facilitates protein maturation, increases ASIC2 surface expression in vascular smooth muscle cells [93]. Similar mechanisms may also regulate ASIC biogenesis in disease conditions. In one study, MCAO reduces ASIC1a expression levels within 30 minutes [94]. Although it remains unclear whether ASIC1a trafficking is affected in this paradigm, the result suggests that altered ASIC biogenesis regulates ischemia-induced neuronal injury. In addition, increased oxidation may also regulate ASIC trafficking. $\mathrm{H}_{2} \mathrm{O}_{2}$, a reactive oxygen species (ROS), reduces ASIC1a surface expression [95]. It will be interesting to see whether factors regulating ER stress and/or ROS production regulate ASIC1a surface and dendritic trafficking, and to ask how proteins that control the secretory process affect ASIC trafficking and function.

\section{Motifs within ASICs}

All ASICs contain a C-terminal PDZ binding motif. The C-termini of ASIC1 and ASIC2 are DFTC and EIAC, respectively, and more closely resemble that of a type II motif $[67,96,97]$. In contrast, the last four amino acid of ASIC3, VTRL, fits a canonical type I motif [98]. Through the interaction with several PDZ proteins, these motifs regulate ASIC surface expression, synaptic targeting, and channel function (see next section). Another motif identified within the Cterminus of ASIC1a is a LDDVK motif, which functions as an $\alpha$-actinin interacting motif [99]. Mutating this motif has no apparent effect on ASIC1a surface expression, but slight decreases the $\mathrm{pH}$ sensitivity of ASIC1a. At the N-terminus, all ASICs contain a HisGly (HG) motif, which is a signature motif for EDA family ion channels. In ENaCs, mutating the HG motif reduces the open probability of these channels 
$[100,101]$, suggesting its importance in channel gating. The functional significance of the HG motif in ASICs, however, remains unclear. Other than these three examples, we know little about motifs in ASICs. The characterization of novel motifs within ASICs will help us to understand molecular mechanisms regulating these channels, facilitate the identification of new ASIC interacting proteins, and also provide potential sites for intervening acidosis-induced changes.

\section{Proteins regulating ASICS}

Through direct association or protein modification, effector proteins and/or signaling molecules regulate the function of various ion channels. The number of ASICregulators has kept increasing in the past few years. A summary of these effector proteins and signaling molecules is listed below.

\section{Effector proteins}

$\boldsymbol{\alpha}$-Actinin $\alpha$-Actinin is one family of molecules important for linking the actin cytoskeleton with the synaptic complex. Actinin-1 and -4 interact with ASIC1a through a C-terminal LDDVK motif [99]. In heterologous cells, the interaction with actinin-4 but not that with actinin-1 regulates ASIC1a current properties; $\mathrm{pH}$ sensitivity and recovery from desensitization are increased with actinin-4 overexpression. In hippocampal neurons, knocking down actinin 1, 2 and 4 together increases ASIC current density and reduces $\mathrm{pH}_{50}$ [99].

AKAP150 AKAP150 is the major AKAP for anchoring PKA to synapses [102]. AKAP150 associates and colocalizes with ASIC1a and ASIC2a, and increases ASIC1a current [70]. The effect on current is likely due to a PKA-dependent mechanism. Ht-31, a small peptide that inhibits the association between PKA and AKAP150, reduces acid-activated current in cultured cortical neurons [70].

Annexin II light chain/p11 p11 is an adaptor protein which forms a complex with Annexin II [103]. p11/ Annexin II complex interacts with multiple ion channels and regulates their trafficking. p11 interacts with the $\mathrm{N}$ terminus of ASIC1a but not with other ASICs [104]. Through this interaction, p11 increases ASIC1a surface expression and current density without changing other properties of the current.

Chaperones Several chaperone proteins interact with ASICs with different specificity. Hsp90 and Grp4 interact with ASIC1a, Hsc70 interacts with ASIC2a, Grp78 and calnexin interact with both ASIC1a and 2a [105]. Knocking down Hsc70 increases ASIC2a surface expression in both glioma and muscle cells [93,105]. The detailed molecular mechanism for how chaperones affect ASIC trafficking and function remains to be clarified.

CIPP (channel-interacting PDZ domain protein) CIPP contains four PDZ domains. Through its fourth PDZ, CIPP interacts with ASIC3 and increases its current density [106]. This effect is most likely due to an increase in the number of functional channels because CIPP appears to have no effect on open probability or single channel conductance of ASIC3.

Lin-7b Lin-7b associates with ASIC3 in COS cells [98]. This interaction increases surface expression and current amplitude of ASIC3.

MAGI-1b MAGI-1b is a member of the MAGUK (membrane-associated guanylate kinases) family. MAGI1b co-immunoprecipitates with ASIC3 in COS cells [98]. The functional effect of MAGI-1b on ASIC3 remains unclear.

NHERF $\left(\mathrm{Na}+/ \mathrm{H}^{+}\right.$exchanger regulatory factor) Both NHERF1 and NHERF2 interact with ASIC3 via PDZ dependent interactions [107]. In COS cells, NHERF1 alters the distribution of ASIC3, which becomes colocalized with the ezrin/radixin/moesin family proteins. The interaction with NHERF1 increases surface expression, peak amplitude and sustained current of ASIC3. In addition, PKC enhances the association between NHERF1 and ASIC3 through the phosphorylation of serine 523 on ASIC3.

PICK1 (Protein-interacting with C-kinase) PICK1 is a scaffolding protein that regulates the trafficking of multiple synaptic receptors [108]. PICK1 interacts with ASIC1a and ASIC2 through the PDZ-dependent interactions [67,96]. The interaction between PICK1 and ASIC1a increases surface expression of ASIC1a, and this effect depends upon the BAR domain and lipid binding of PICK1 [109,110]. The interaction between ASIC1a and PICK1 is regulated by protein kinase A (PKA) and protein kinase $\mathrm{C}$ (PKC) (see below).

PIST PIST is a PDZ containing protein that was originally identified as an interactor with TC10, a Rho GTPase [111]. PIST was identified as an ASIC3 interactor in a two-hybrid screening. The functional effect of PIST on ASIC3 is unknown [98].

PSD-95 (Postsynaptic density protein 95) PSD-95 is the primary organizer of the postsynaptic density complex. Through PDZ-dependent interactions, PSD-95 associates with ASIC2a and ASIC3 but not ASIC1a [20,98]. In heterologous cells, the interaction between PSD-95 and ASIC3 
occurs in lipid rafts, and reduces surface expression and current amplitude of ASIC3 [98,112]. In hippocampal slices, PSD-95 is important for synaptic targeting of ASIC2a, which in turn increases the synaptic levels of ASIC1a and acidosis-induced $\left[\mathrm{Ca}^{2+}\right]_{i}$ responses in spines [20].

Stomatin and Stomatin-like protein 3 (SLP3) Stomatin and SLP3 co-immunoprecipitate with ASIC1a, 2a and 3 in heterologous cells [113-115]. Dimerization of stomatin is essential for its interaction with ASICs [116]. Stomatin has no effect on ASIC1a current, increases the rate of desensitization of ASIC2a, and drastically reduces ASIC3 current. SLP3, which forms a complex with both stomatin and ASIC2a, reduces ASIC2a current without affecting its surface expression. In the SLP3 knockout mice, ASIC current is increased in parallel with a disruption of touch sensation.

\section{Signaling molecules regulating ASICS}

$\mathrm{Ca}^{2+} /$ calmodulin-dependent protein kinase II (CaMKII) The C-terminus of ASIC1a contains a KRXS sequence, which can be phosphorylated by CaMKII and PKA. CaMKII phosphorylation of ASIC1a increases its current amplitude and probably contributes to ischemiainduced neuronal death [86]. This finding also suggests that conditions which alter $\left[\mathrm{Ca}^{2+}\right]_{\mathrm{i}}$ levels play an active role in regulating $\mathrm{ASIC} 1 \mathrm{a}$ and consequently acidosisrelated processes. Interestingly, acidosis increases $\left[\mathrm{Ca}^{2+}\right]_{\mathrm{i}}$ via ASIC1a, and manipulating ASIC1a expression levels regulates CaMKII phosphorylation [19]. These findings suggest a possible positive feedback mechanism contributing to acidosis-induced changes in neural plasticity and excitotoxicity.

Protein kinase A (PKA) PKA phosphorylates ASIC1a at the same site as CaMKII. PKA phosphorylation of ASIC1a inhibits its association with PICK1 and reduces the clustering of ASIC1a inside the cell [117]. Further study is needed to clarify how PKA regulates ASIC function in neurons, and whether PKA and CaMKII share similar mechanisms in regulating acidosis-induced changes.

Phosphoinositide 3-kinase (PI3K) Activation of PI3K by BDNF results in increased surface expression of ASIC1a and ASIC2a, but not that of ASIC1b or ASIC3 [89]. This effect was attributed to increased insertion as opposed to a reduction in endocytosis of ASIC1a. The serine 25 site in ASIC1a is important for the observed effect. An ASIC1a S25A mutant has reduced surface expression and abolishes BDNF-induced increase in current. Ser25 phosphorylation apparently contributes to part of brain derived neurotrophic factor (BDNF)induced hypersensitivity to painful stimuli. These results establish a connection between neutrophin signaling and ASIC regulation. One remaining question is which kinase directly phosphorylates the Ser 25 site in ASIC1a, which does not appear to fit the consensus phosphorylation sites of the common kinases.

Insulin signaling Insulin deprivation increases ASIC1a surface trafficking and potentiates acid-activated currents [68]. Insulin initiates multiple downstream signaling events, including the activation of PI3K/Akt pathway [118]. However, since PI3K activation leads to increased ASIC1a trafficking [89], the effect of insulin is most likely mediated by an PI3K-independent pathway.

Protein kinase $\mathbf{C}$ (PKC) PKC regulates both ASIC1a and ASIC2a. In Xenopus oocytes, PKC activation reduces current amplitude of human ASIC1a [119]. Serine 40 and 499 appear to be involved. An S40E mutant shows reduced current (mimics the effect of PKC), while an S40A mutant abolishes the effect of PKC activators. Unlike serine 40, both S499A and S499E show reduced current amplitude, and S499A does not abolish the effect of PKC activation. These effects on currents are unlikely a result of reduced expression, because all mutants show similar protein levels in the total membrane fraction. However, it remains to see whether the surface trafficking of ASIC1a is affected by PKC. In contrast to the findings in oocytes, PKC increases ASIC current in cultured cortical neurons [110]. This effect may due to ASIC2. In COS cells, PKC activation increases ASIC2a current [120]. Threonine 39 in ASIC2a, the equivalent of serine 40 in ASIC1a, is important for the effect of PKC on ASIC2a. In addition, the potentiation of ASIC current by PKC depends upon an interaction with PICK1.

Reactive oxygen species (ROS) Many diseases increase ROS production. Since ASICs contain a large number of cysteines, several studies have studied whether redox reagents affect ASIC channel properties. Reducing reagents increase ASIC1a current while oxidizing reagents have the opposite effect $[88,121,122]$. These effects are largely due to modifications in the extracellular domain. In contrast to oxidizing reagents, nitric oxide (NO) potentiates ASIC1a, $-1 \mathrm{~b},-2 \mathrm{a}$, and -3 through the modulation of extracellular domain [123]. In addition, ROS can target intracellular C-terminal cysteines. $\mathrm{H}_{2} \mathrm{O}_{2}$ induces the formation of intersubunit disulfide bonds between C-terminal cysteines within ASIC1a, and reduces its surface expression [95].

\section{Summary and speculations}

Research in recent years has demonstrated that acidosis and ASICs are an important contributor to multiple 
neurological diseases. To better understand the role of ASICs in diseases, it is now necessary to answer some fundamental questions regarding the regulation and function of ASICs. A few of these questions are discussed in this review and/or summarized below:

- What is the contribution of ASICs to synaptic transmission?

- What is the dynamics of acidosis-induced synaptic remodeling?

- How do acidosis and ASICs contribute to synaptic plasticity in diseases?

- Are there endogenous ASIC ligands other than protons?

- How does the exact channel stoichiometry affect ASIC function? For exmaple, are channels containing 1 ASIC1a and 2 ASIC2a subunits behave the same as channels containing $2 \mathrm{ASIC} 1 \mathrm{a}$ and $1 \mathrm{ASIC} 2 \mathrm{a}$ ? Or do the heteromeric channels prefer one stoichiometry over another?

- What is the role of altered ASIC trafficking in synaptic remodeling and diseases?

- What novel motifs and accessory proteins contribute to ASIC regulation?

- What signaling pathways regulate ASIC trafficking and function?

The list apparently can go on longer. However, these are some of the basic ones on ASIC biology. Answering these questions will bring novel insight into the regulation of ASICs and their role in neuron physiology, and will lay the groundwork for targeting these ion channels in diseases.

\footnotetext{
Abbreviations

AMPA: 2-amino-3-(3-hydroxy-5-methyl-isoxazol-4-yl)propanoic acid; ASIC: Acid-sensing ion channel; CaMKII: $\mathrm{Ca}^{2+} /$ calmodulin-dependent protein kinase II; CHO: Chinese hamster ovary; DEG: Degenerin; EDA: ENaC/DEG/ ASIC/; ENaC: Epithelial sodium channels; ER: Endoplasmic reticulum; ERG: Electroretinogram; MCAO: Middle cerebral artery occlusion; MAGI1b: (membrane-associated guanylate kinases) family; NHERF: $\mathrm{Na}^{+} / \mathrm{H}^{+}$ exchanger regulatory factor; NMDA: N-Methyl-D-aspartic acid; PDZ: PSD-95/ disc large tumor suppressor/zonula occludens-1; PI3K: Phosphoinositide 3kinase; PICK1: Protein-interacting with C kinase; PKA: Protein kinase A; PKC: Protein kinase C; PSD-95: Postsynaptic density protein 95; ROS: Reactive oxygen species; SLP3: Stomatin-like protein 3; VGCC: Voltage gated calcium channel.
}

\section{Competing interest}

The author declare that he has no conflict of interest.

\section{Acknowledgements}

I thank Drs. Xiangping Chu and Mike T Lin for critical reading of this manuscript. This work is supported by startup funds from the University of South Alabama.

Received: 16 November 2012 Accepted: 20 December 2012 Published: 2 January 2013

\section{References}

1. Noël J, Salinas M, Baron A, Diochot S, Deval E, Lingueglia E: Current perspectives on acid-sensing ion channels: new advances and therapeutic implications. Expert Rev Clin Pharmacol 2010, 3:331-346.

2. Sluka KA, Winter OC, Wemmie JA: Acid-sensing ion channels: a new target for pain and CNS diseases. Curr Opin Drug Discov Devel 2009, 12:693-704.

3. Gonzales EB, Kawate T, Gouaux E: Pore architecture and ion sites in acidsensing ion channels and P2X receptors. Nature 2009, 460:599-604.

4. Jasti J, Furukawa H, Gonzales EB, Gouaux E: Structure of acid-sensing ion channel 1 at 1.9 A resolution and low pH. Nature 2007, 449:316-323.

5. Waldmann R, Champigny G, Bassilana F, Heurteaux C, Lazdunski M: A protongated cation channel involved in acid-sensing. Nature 1997, 386:173-177.

6. Hoagland EN, Sherwood TW, Lee KG, Walker CJ, Askwith CC: Identification of a calcium permeable human acid-sensing ion channel 1 transcript variant. J Biol Chem 2011, 285:41852-41862.

7. Bassler EL, Ngo-Anh TJ, Geisler HS, Ruppersberg JP, Grunder S: Molecular and functional characterization of acid-sensing ion channel (ASIC) $1 \mathrm{~b}$. J Biol Chem 2001, 276:33782-33787.

8. Zhang $P$, Canessa CM: Single channel properties of rat acid-sensitive ion channel-1alpha, $-2 \mathrm{a}$, and -3 expressed in Xenopus oocytes. J Gen Physiol 2002, 120:553-566.

9. Sherwood TW, Lee KG, Gormley MG, Askwith CC: Heteromeric acid-sensing ion channels (ASICs) composed of ASIC2b and ASIC1a display novel channel properties and contribute to acidosis-induced neuronal death. J Neurosci 2011, 31:9723-9734.

10. Baconguis I, Gouaux E: Structural plasticity and dynamic selectivity of acidsensing ion channel-spider toxin complexes. Nature 2012, 489:400-405.

11. Babini E, Paukert M, Geisler HS, Grunder S: Alternative splicing and interaction with di- and polyvalent cations control the dynamic range of acid-sensing ion channel 1 (ASIC1). J Biol Chem 2002, 277:41597-41603.

12. Benson CJ, Xie J, Wemmie JA, Price MP, Henss JM, Welsh MJ, Snyder PM: Heteromultimers of DEG/ENaC subunits form $\mathrm{H}+-$ gated channels in mouse sensory neurons. Proc Natl Acad Sci USA 2002, 99:2338-2343.

13. Sutherland SP, Benson CJ, Adelman JP, McCleskey EW: Acid-sensing ion channel 3 matches the acid-gated current in cardiac ischemia-sensing neurons. Proc Natl Acad Sci USA 2001, 98:711-716.

14. Yagi J, Wenk HN, Naves LA, McCleskey EW: Sustained currents through ASIC3 ion channels at the modest $\mathrm{pH}$ changes that occur during myocardial ischemia. Circ Res 2006, 99:501-509.

15. Hesselager M, Timmermann DB, Ahring PK: pH Dependency and desensitization kinetics of heterologously expressed combinations of acid-sensing ion channel subunits. J Biol Chem 2004, 279:11006-11015.

16. Delaunay A, Gasull X, Salinas M, Noel J, Friend V, Lingueglia E, Deval E: Human ASIC3 channel dynamically adapts its activity to sense the extracellular $\mathrm{pH}$ in both acidic and alkaline directions. Proc Natl Acad Sci USA 2012, 109:13124-13129.

17. Chu XP, Xiong ZG: Physiological and pathological functions of Acidsensing ion channels in the central nervous system. Curr Drug Targets 2012, 13:263-271.

18. Grunder S, Chen X: Structure, function, and pharmacology of acidsensing ion channels (ASICs): focus on ASIC1a. Int J Physiol Pathophysiol Pharmacol 2010, 2:73-94

19. Zha XM, Wemmie JA, Green SH, Welsh MJ: Acid-sensing ion channel 1a is a postsynaptic proton receptor that affects the density of dendritic spines. Proc Natl Acad Sci USA 2006, 103:16556-16561.

20. Zha XM, Costa V, Harding AMS, Reznikov L, Benson CJ, Welsh MJ: ASIC2 Subunits target acid-sensing ion channels to the synapse via an association with PSD-95. J Neurosci 2009, 29:8438-8446.

21. Jing $L$, Chu XP, Jiang YQ, Collier DM, Wang B, Jiang Q, Snyder PM, Zha XM: $\mathrm{N}$-glycosylation of acid-sensing ion channel 1a regulates its trafficking and acidosis-induced spine remodeling. J Neurosci 2012, 32:4080-4091.

22. Bohlen CJ, Chesler AT, Sharif-Naeini R, Medzihradszky KF, Zhou S, King D, Sanchez EE, Burlingame AL, Basbaum Al, Julius D: A heteromeric Texas coral snake toxin targets acid-sensing ion channels to produce pain. Nature 2011, 479:410-414.

23. Escoubas P, De Weille JR, Lecoq A, Diochot S, Waldmann R, Champigny G, Moinier D, Menez A, Lazdunski M: Isolation of a tarantula toxin specific for a class of proton-gated $\mathrm{Na}+$ channels. J Biol Chem 2000, 275:25116-25121.

24. Diochot S, Baron A, Salinas M, Douguet D, Scarzello S, Dabert-Gay AS, Debayle $D$, Friend V, Alloui A, Lazdunski M, Lingueglia E: Black mamba venom peptides target acid-sensing ion channels to abolish pain. Nature 2012, 490:552-555. 
25. Dube GR, Lehto SG, Breese NM, Baker SJ, Wang X, Matulenko MA, Honore P, Stewart AO, Moreland RB, Brioni JD: Electrophysiological and in vivo characterization of A-317567, a novel blocker of acid sensing ion channels. Pain 2005, 117:88-96.

26. Baron A, Waldmann R, Lazdunski M: ASIC-like, proton-activated currents in rat hippocampal neurons. J Physio/ 2002, 539:485-494.

27. Chen X, Kalbacher H, Grunder S: The tarantula toxin psalmotoxin 1 inhibits acid-sensing ion channel (ASIC) 1a by increasing its apparent $\mathrm{H}+$ affinity. J Gen Physiol 2005, 126:71-79.

28. Jiang $H$, Zha XM, Chu XP: Inhibition of human acid-sensing ion channel 1b by zinc. Int J Physiol Pathophysiol Pharmacol 2012, 4:84-93.

29. Garcia-Anoveros J, Derfler B, Neville-Golden J, Hyman BT, Corey DP: BNaC1 and $\mathrm{BNaC2}$ constitute a new family of human neuronal sodium channels related to degenerins and epithelial sodium channels. Proc Natl Acad Sci USA 1997, 94:1459-1464.

30. Price MP, Snyder PM, Welsh MJ: Cloning and expression of a novel human brain $\mathrm{Na}+$ channel. J Biol Chem 1996, 271:7879-7882.

31. Waldmann R, Champigny G, Voilley N, Lauritzen I, Lazdunski M: The mammalian degenerin MDEG, an amiloride-sensitive cation channel activated by mutations causing neurodegeneration in Caenorhabditis elegans. J Biol Chem 1996, 271:10433-10436.

32. Yu Y, Chen Z, Li WG, Cao H, Feng EG, Yu F, Liu H, Jiang H, Xu TL: A nonproton ligand sensor in the acid-sensing ion channel. Neuron 2010, 68:61-72.

33. Diochot S, Baron A, Rash LD, Deval E, Escoubas P, Scarzello S, Salinas M, Lazdunski M: A new sea anemone peptide, APETx2, inhibits ASIC3, a major acid-sensitive channel in sensory neurons. EMBO J 2004, 23:1516-1525.

34. Dubinnyi MA, Osmakov DI, Koshelev SG, Kozlov SA, Andreev YA, Zakaryan NA, Dyachenko IA, Bondarenko DA, Arseniev AS, Grishin EV: Lignan from thyme possesses inhibitory effect on asic3 channel current. J Biol Chem 2012, 287:32993-33000.

35. Waldmann R, Bassilana F, De Weille J, Champigny G, Heurteaux C, Lazdunski M: Molecular cloning of a non-inactivating proton-gated $\mathrm{Na}+$ channel specific for sensory neurons. J Biol Chem 1997, 272:20975-20978.

36. Chagot B, Escoubas P, Diochot S, Bernard C, Lazdunski M, Darbon H: Solution structure of APETx2, a specific peptide inhibitor of ASIC3 proton-gated channels. Protein Sci 2005, 14:2003-2010.

37. Grunder S, Geissler HS, Bassler EL, Ruppersberg JP: A new member of acidsensing ion channels from pituitary gland. Neuroreport 2000, 11:1607-1611.

38. Wemmie JA, Price MP, Welsh MJ: Acid-sensing ion channels: advances, questions and therapeutic opportunities. Trends Neurosci 2006, 29:578-587.

39. Askwith CC, Cheng C, Ikuma M, Benson C, Price MP, Welsh MJ: Neuropeptide FF and FMRFamide potentiate acid-evoked currents from sensory neurons and proton-gated DEG/ENaC channels. Neuron 2000, 26:133-141.

40. Sherwood TW, Askwith CC: Endogenous arginine-phenylalanine-amiderelated peptides alter steady-state desensitization of ASIC1a. J Biol Chem 2008, 283:1818-1830.

41. Sherwood TW, Askwith CC: Dynorphin opioid peptides enhance acidsensing ion channel 1a activity and acidosis-induced neuronal death. J Neurosci 2009, 29:14371-14380.

42. Duan B, Wang YZ, Yang T, Chu XP, Yu Y, Huang Y, Cao H, Hansen J, Simon $\mathrm{RP}$, Zhu MX, et al: Extracellular spermine exacerbates ischemic neuronal injury through sensitization of ASIC1a channels to extracellular acidosis. J Neurosci 2011, 31:2101-2112.

43. Alvarez De La Rosa D, Zhang P, Shao D, White F, Canessa CM: Functional implications of the localization and activity of acid-sensitive channels in rat peripheral nervous system. Proc Natl Acad Sci USA 2002, 99:2326-2331.

44. Wemmie JA, Chen J, Askwith CC, Hruska-Hageman AM, Price MP, Nolan BC, Yoder PG, Lamani E, Hoshi T, Freeman JH Jr, Welsh MJ: The acid-activated ion channel ASIC contributes to synaptic plasticity, learning, and memory. Neuron 2002, 34:463-477.

45. Askwith CC, Wemmie JA, Price MP, Rokhlina T, Welsh MJ: Acid-sensing ion channel 2 (ASIC2) modulates ASIC1 $\mathrm{H}+$-activated currents in hippocampal neurons. J Biol Chem 2004, 279:18296-18305.

46. Gao J, Wu LJ, Xu L, Xu TL: Properties of the proton-evoked currents and their modulation by $\mathrm{Ca} 2+$ and $\mathrm{Zn} 2+$ in the acutely dissociated hippocampus CA1 neurons. Brain Res 2004, 1017:197-207.

47. Weng JY, Lin YC, Lien CC: Cell type-specific expression of acid-sensing ion channels in hippocampal interneurons. J Neurosci 2010, 30:6548-6558.

48. Lin YC, Liu YC, Huang YY, Lien CC: High-density expression of Ca2 + -permeable ASIC1a channels in NG2 glia of rat hippocampus. PLOS One 2010, 5:12665
49. Lin W, Ogura T, Kinnamon SC: Acid-activated cation currents in rat vallate taste receptor cells. J Neurophysio/ 2002, 88:133-141.

50. Hildebrand MS, De Silva MG, Klockars T, Rose E, Price M, Smith RJ, McGuirt WT, Christopoulos H, Petit C, Dahl HH: Characterisation of DRASIC in the mouse inner ear. Hear Res 2004, 190:149-160.

51. Ugawa S, Inagaki A, Yamamura H, Ueda T, Ishida Y, Kajita K, Shimizu H, Shimada S: Acid-sensing ion channel-1b in the stereocilia of mammalian cochlear hair cells. Neuroreport 2006, 17:1235-1239.

52. Ettaiche M, Guy N, Hofman P, Lazdunski M, Waldmann R: Acid-sensing ion channel 2 is important for retinal function and protects against lightinduced retinal degeneration. J Neurosci 2004, 24:1005-1012.

53. Grifoni SC, Jernigan NL, Hamilton G, Drummond HA: ASIC proteins regulate smooth muscle cell migration. Microvasc Res 2008, 75:202-210.

54. Friese MA, Craner MJ, Etzensperger R, Vergo S, Wemmie JA, Welsh MJ, Vincent A, Fugger L: Acid-sensing ion channel-1 contributes to axonal degeneration in autoimmune inflammation of the central nervous system. Nat Med 2007, 13:1483-1489.

55. Berdiev BK, Xia J, McLean LA, Markert JM, Gillespie GY, Mapstone TB, Naren AP, Jovov B, Bubien JK, Ji HL, et al: Acid-sensing ion channels in malignant gliomas. J Biol Chem 2003, 278:15023-15034.

56. Bubien JK, Keeton DA, Fuller CM, Gillespie GY, Reddy AT, Mapstone TB, Benos DJ: Malignant human gliomas express an amiloride-sensitive $\mathrm{Na}+$ conductance. Am J Physiol 1999, 276:C1405-C1410.

57. Alvarez De La Rosa D, Krueger SR, Kolar A, Shao D, Fitzsimonds RM, Canessa CM: Distribution, subcellular localization and ontogeny of ASIC1 in the mammalian central nervous system. J Physio/ 2003, 546:77-87.

58. Coryell MW, Ziemann AE, Westmoreland PJ, Haenfler JM, Kurjakovic Z, Zha XM, Price M, Schnizler MK, Wemmie JA: Targeting ASIC1a reduces innate fear and alters neuronal activity in the fear circuit. Biol Psychiatry 2007, 62:1140-1148

59. Wemmie JA, Askwith CC, Lamani E, Cassell MD, Freeman JH Jr, Welsh MJ: Acidsensing ion channel 1 is localized in brain regions with high synaptic density and contributes to fear conditioning. J Neurosci 2003, 23:5496-5502.

60. Allen NJ, Attwell D: Modulation of ASIC channels in rat cerebellar Purkinje neurons by ischaemia-related signals. J Physiol 2002, 543:521-529.

61. Jiang Q, Li MH, Papasian CJ, Branigan D, Xiong ZG, Wang JQ, Chu XP: Characterization of acid-sensing ion channels in medium spiny neurons of mouse striatum. Neuroscience 2009, 162:55-66.

62. Chu XP, Wemmie JA, Wang WZ, Zhu XM, Saugstad JA, Price MP, Simon RP, Xiong ZG: Subunit-dependent high-affinity zinc inhibition of acid-sensing ion channels. J Neurosci 2004, 24:8678-8689.

63. Li M, Kratzer E, Inoue K, Simon RP, Xiong ZG: Developmental change in the electrophysiological and pharmacological properties of acid-sensing ion channels in CNS neurons. J Physiol 2010, 588:3883-3900.

64. Li M, Inoue K, Branigan D, Kratzer E, Hansen JC, Chen JW, Simon RP, Xiong ZG: Acid-sensing ion channels in acidosis-induced injury of human brain neurons. J Cereb Blood Flow Metab 2010, 30:1247-1260.

65. Price MP, Lewin GR, Mcllwrath SL, Cheng C, Xie J, Heppenstall PA, Stucky CL, Mannsfeldt AG, Brennan TJ, Drummond HA, et al: The mammalian sodium channel BNC1 is required for normal touch sensation. Nature 2000, 407:1007-1011.

66. Price MP, Mcllwrath SL, Xie J, Cheng C, Qiao J, Tarr DE, Sluka KA, Brennan TJ, Lewin GR, Welsh MJ: The DRASIC cation channel contributes to the detection of cutaneous touch and acid stimuli in mice. Neuron 2001, 32:1071-1083.

67. Duggan A, Garcia-Anoveros J, Corey DP: The PDZ domain protein PICK and the sodium channel $\mathrm{BNaC} 1$ interact and localize at mechanosensory terminals of dorsal root ganglion neurons and dendrites of central neurons. J Biol Chem 2002, 277:5203-5208.

68. Chai S, Li M, Branigan D, Xiong ZG, Simon RP: Activation of acid-sensing ion channel 1a (ASIC1a) by surface trafficking. J Biol Chem 2010, 285:13002-13011.

69. Jovov B, Tousson A, McMahon LL, Benos DJ: Immunolocalization of the acid-sensing ion channel $2 \mathrm{a}$ in the rat cerebellum. Histochem Cell Biol 2003, 119:437-446.

70. Chai S, Li M, Lan J, Xiong ZG, Saugstad JA, Simon RP: A kinase-anchoring protein 150 and calcineurin are involved in regulation of acid-sensing ion channels ASIC1a and ASIC2a. J Biol Chem 2007, 282:22668-22677.

71. Jing $L$, Jiang $Y Q$, Jiang $Q$, Wang $B$, Chu XP, Zha XM: Interaction between the first transmembrane domain and the thumb of acid-sensing lon channel 1a is critical for its N-glycosylation and trafficking. PLoS One 2011, 6:e26909. 
72. Vergo S, Craner MJ, Etzensperger R, Attfield K, Friese MA, Newcombe J, Esiri M, Fugger L: Acid-sensing ion channel 1 is involved in both axonal injury and demyelination in multiple sclerosis and its animal model. Brain 2011, 134:571-584.

73. Xiong ZG, Zhu XM, Chu XP, Minami M, Hey J, Wei WL, MacDonald JF, Wemmie JA, Price MP, Welsh MJ, Simon RP: Neuroprotection in ischemia: blocking calcium-permeable acid-sensing ion channels. Cell 2004, 118:687-698.

74. Samways DS, Harkins AB, Egan TM: Native and recombinant ASIC1a receptors conduct negligible Ca2+ entry. Cell Calcium 2009, 45:319-325.

75. Herrera Y, Katnik C, Rodriguez JD, Hall AA, Willing A, Pennypacker KR, Cuevas J: Sigma-1 receptor modulation of acid-sensing ion channel a (ASIC1a) and ASIC1a-induced Ca2+ influx in rat cortical neurons. J Pharmacol Exp Ther 2008, 327:491-502.

76. Magnotta VA, Heo HY, Dlouhy BJ, Dahdaleh NS, Follmer RL, Thedens DR, Welsh MJ, Wemmie JA: Detecting activity-evoked $\mathrm{pH}$ changes in human brain. Proc Natl Acad Sci U S A 2012,

77. Cho JH, Askwith CC: Presynaptic release probability is increased in hippocampal neurons from ASIC1 knockout mice. J Neurophysiol 2008, 99:426-441.

78. Ettaiche M, Deval E, Cougnon M, Lazdunski M, Voilley N: Silencing acidsensing ion channel 1a alters cone-mediated retinal function. J Neurosci 2006, 26:5800-5809.

79. Li T, Yang Y, Canessa CM: Impact of recovery from desensitization on acid sensing ion channel-1a (ASIC1a) Current and Response to highfrequency stimulation. J Biol Chem 2012, 287:40680-40689.

80. Lu Y, Zha XM, Kim EY, Schachtele S, Dailey ME, Hall DD, Strack S, Green SH, Hoffman DA, Hell JW: A kinase anchor protein 150 (AKAP150)-associated protein kinase A limits dendritic spine density. J Biol Chem 2011, 286:26496-26506

81. Smith ML, Von Hanwehr R, Siesjo BK: Changes in extra- and intracellular $\mathrm{pH}$ in the brain during and following ischemia in hyperglycemic and in moderately hypoglycemic rats. J Cereb Blood Flow Metab 1986, 6:574-583.

82. Pignataro G, Simon RP, Xiong ZG: Prolonged activation of ASIC1a and the time window for neuroprotection in cerebral ischaemia. Brain 2007, 130:151-158.

83. Wong M: Modulation of dendritic spines in epilepsy: cellular mechanisms and functional implications. Epilepsy Behav 2005, 7:569-577.

84. Brown CE, Murphy TH: Livin'on the edge: imaging dendritic spine turnover in the peri-infarct zone during ischemic stroke and recovery. Neuroscientist 2008, 14:139-146.

85. Isaev NK, Stelmashook EV, Plotnikov EY, Khryapenkova TG, Lozier ER, Doludin YV, Silachev DN, Zorov DB: Role of acidosis, NMDA receptors, and acid-sensitive ion channel 1a (ASIC1a) in neuronal death induced by ischemia. Biochemistry (Mosc) 2008, 73:1171-1175.

86. Gao J, Duan B, Wang DG, Deng XH, Zhang GY, Xu L, Xu TL: Coupling between NMDA receptor and acid-sensing ion channel contributes to ischemic neuronal death. Neuron 2005, 48:635-646.

87. Ziemann AE, Schnizler MK, Albert GW, Severson MA, Howard lii MA, Welsh MJ, Wemmie JA: Seizure termination by acidosis depends on ASIC1a. Nat Neurosci 2008, 11:816-822.

88. Cho JH, Askwith CC: Potentiation of acid-sensing ion channels by sulfhydryl compounds. Am J Physiol Cell Physiol 2007, 292:C2161-C2174.

89. Duan B, Liu DS, Huang Y, Zeng WZ, Wang X, Yu H, Zhu MX, Chen ZY, Xu TL: $\mathrm{PI} 3-k i n a s e / A k t$ pathway-regulated membrane insertion of acid-sensing ion channel 1a underlies BDNF-induced pain hypersensitivity. J Neurosci 2012, 32:6351-6363.

90. Kadurin I, Golubovic A, Leisle L, Schindelin H, Grunder S: Differential effects of N-glycans on surface expression suggest structural differences between the acid-sensing ion channel (ASIC) 1a and ASIC1b. Biochem J 2008, 412:469-475.

91. Prescher JA, Bertozzi CR: Chemical technologies for probing glycans. Cell 2006, 126:851-854

92. Saugstad JA, Roberts JA, Dong J, Zeitouni S, Evans RJ: Analysis of the membrane topology of the acid-sensing ion channel 2a. J Biol Chem 2004, 279:55514-55519.

93. Grifoni SC, McKey SE, Drummond HA: Hsc70 regulates cell surface ASIC2 expression and vascular smooth muscle cell migration. Am J Physiol Heart Circ Physiol 2008, 294:H2022-H2030.

94. Pignataro G, Cuomo O, Esposito E, Sirabella R, Di Renzo G, Annunziato L: ASIC1a contributes to neuroprotection elicited by ischemic preconditioning and postconditioning. Int J Physiol Pathophysiol Pharmacol 2011, 3:1-8.
95. Zha XM, Wang R, Collier DM, Snyder PM, Wemmie JA, Welsh MJ: Oxidant regulated inter-subunit disulfide bond formation between ASIC1a subunits. Proc Natl Acad Sci USA 2009, 106:3573-3578.

96. Hruska-Hageman AM, Wemmie JA, Price MP, Welsh MJ: Interaction of the synaptic protein PICK1 (protein interacting with C kinase 1) with the non-voltage gated sodium channels BNC1 (brain Na + channel 1) and ASIC (acid-sensing ion channel). Biochem J 2002, 361:443-450.

97. Songyang Z, Fanning AS, Fu C, Xu J, Marfatia SM, Chishti AH, Crompton A, Chan AC, Anderson JM, Cantley LC: Recognition of unique carboxylterminal motifs by distinct PDZ domains. Science 1997, 275:73-77.

98. Hruska-Hageman AM, Benson CJ, Leonard AS, Price MP, Welsh MJ: PSD-95 and Lin-7b interact with acid-sensing ion channel-3 and have opposite effects on $\mathrm{H}+-$ gated current. J Biol Chem 2004, 279:46962-46968.

99. Schnizler MK, Schnizler K, Zha XM, Hall DD, Wemmie JA, Hell JW, Welsh MJ: The cytoskeletal protein \{alpha\}-actinin regulates acid-sensing ion channel 1a through a C-terminal Interaction. J Bio/ Chem 2009, 284:2697-2705.

100. Grunder S, Firsov D, Chang SS, Jaeger NF, Gautschi I, Schild L, Lifton RP, Rossier BC: A mutation causing pseudohypoaldosteronism type 1 identifies a conserved glycine that is involved in the gating of the epithelial sodium channel. EMBO J 1997, 16:899-907.

101. Grunder S, Jaeger NF, Gautschi I, Schild L, Rossier BC: Identification of a highly conserved sequence at the $\mathrm{N}$-terminus of the epithelial $\mathrm{Na}+$ channel alpha subunit involved in gating. Pflugers Arch 1999, 438:709-715.

102. Dell'Acqua ML, Smith KE, Gorski JA, Horne EA, Gibson ES, Gomez LL: Regulation of neuronal PKA signaling through AKAP targeting dynamics. Eur J Cell Biol 2006, 85:627-633.

103. Svenningsson P, Greengard P: p11 (S100A10)-an inducible adaptor protein that modulates neuronal functions. Curr Opin Pharmacol 2007, 7:27-32.

104. Donier E, Rugiero F, Okuse K, Wood JN: Annexin II light chain p11 promotes functional expression of acid-sensing ion channel ASIC1a. J Biol Chem 2005, 280:38666-38672

105. Vila-Carriles WH, Zhou ZH, Bubien JK, Fuller CM, Benos DJ: Participation of the chaperone $\mathrm{Hsc70}$ in the trafficking and functional expression of ASIC2 in glioma cells. J Biol Chem 2007, 282:34381-34391.

106. Anzai N, Deval E, Schaefer L, Friend V, Lazdunski M, Lingueglia E: The multivalent PDZ domain-containing protein CIPP is a partner of acid-sensing ion channel 3 in sensory neurons. J Biol Chem 2002, 277:16655-16661.

107. Deval E, Friend V, Thirant C, Salinas M, Jodar M, Lazdunski M, Lingueglia E: Regulation of sensory neuron-specific acid-sensing ion channel 3 by the adaptor protein $\mathrm{Na}+/ \mathrm{H}+$ exchanger regulatory factor-1. J Biol Chem 2006, 281:1796-1807.

108. Xu J, Xia J: Structure and function of PICK1. Neurosignals 2006, 15:190-201.

109. Jin W, Shen C, Jing L, Zha XM, Xia J: PICK1 regulates the trafficking of ASIC $1 a$ and acidotoxicity in a BAR domain lipid binding-dependent manner. Mol Brain 2010, 3:39.

110. Hu ZL, Huang C, Fu H, Jin Y, Wu WN, Xiong QJ, Xie N, Long LH, Chen JG, Wang F: Disruption of PICK1 attenuates the function of ASICs and PKC regulation of ASICs. Am J Physiol Cell Physiol 2010, 299:C1355-C1362.

111. Neudauer CL, Joberty G, Macara IG: PIST: a novel PDZ/coiled-coil domain binding partner for the rho-family GTPase TC10. Biochem Biophys Res Commun 2001, 280:541-547.

112. Eshcol JO, Harding AM, Hattori T, Costa V, Welsh MJ, Benson CJ: Acidsensing ion channel 3 (ASIC3) cell surface expression is modulated by PSD-95 within lipid rafts. Am J Physiol Cell Physiol 2008, 295:C732-C739.

113. Price MP, Thompson RJ, Eshcol JO, Wemmie JA, Benson CJ: Stomatin modulates gating of acid-sensing ion channels. J Biol Chem 2004, 279:53886-53891.

114. Wetzel C, Hu J, Riethmacher D, Benckendorff A, Harder L, Eilers A, Moshourab $R$, Kozlenkov A, Labuz D, Caspani O, et al: A stomatin-domain protein essential for touch sensation in the mouse. Nature 2007, 445:206-209.

115. Lapatsina L, Jira JA, Smith ES, Poole K, Kozlenkov A, Bilbao D, Lewin GR, Heppenstall PA: Regulation of ASIC channels by a stomatin/STOML3 complex located in a mobile vesicle pool in sensory neurons. Open Biol 2012, 2:120096.

116. Brand J, Smith ES, Schwefel D, Lapatsina L, Poole K, Omerbasic D, Kozlenkov A, Behlke J, Lewin GR, Daumke O: A stomatin dimer modulates the activity of acid-sensing ion channels. EMBO J 2012, 31:3635-3646.

117. Leonard AS, Yermolaieva O, Hruska-Hageman A, Askwith CC, Price MP, Wemmie JA, Welsh MJ: CAMP-dependent protein kinase phosphorylation of the acid-sensing ion channel-1 regulates its binding to the protein interacting with C-kinase-1. Proc Natl Acad Sci USA 2003, 100:2029-2034. 
118. Zheng WH, Quirion R: Comparative signaling pathways of insulin-like growth factor-1 and brain-derived neurotrophic factor in hippocampal neurons and the role of the $\mathrm{Pl} 3$ kinase pathway in cell survival. J Neurochem 2004, 89:844-852.

119. Bashari E, Qadri YJ, Zhou ZH, Kapoor N, Anderson SJ, Meltzer RH, Fuller CM Benos DJ: Two PKC consensus sites on human acid-sensing ion channel 1b differentially regulate its function. Am J Physiol Cell Physiol 2009, 296: C372-C384.

120. Baron A, Deval E, Salinas M, Lingueglia E, Voilley N, Lazdunski M: Protein kinase $C$ stimulates the acid-sensing ion channel ASIC2a via the PDZ domain-containing protein PICK1.J Biol Chem 2002, 277:50463-50468.

121. Andrey F, Tsintsadze T, Volkova T, Lozovaya N, Krishtal O: Acid sensing ionic channels: modulation by redox reagents. Biochim Biophys Acta 2005, 1745:1-6.

122. Chu XP, Close N, Saugstad JA, Xiong ZG: ASIC1a-specific modulation of acid-sensing ion channels in mouse cortical neurons by redox reagents. J Neurosci 2006, 26:5329-5339.

123. Cadiou H, Studer M, Jones NG, Smith ES, Ballard A, McMahon SB, McNaughton PA: Modulation of acid-sensing ion channel activity by nitric oxide. J Neurosci 2007, 27:13251-13260.

doi:10.1186/1756-6606-6-1

Cite this article as: Zha: Acid-sensing ion channels: trafficking and synaptic function. Molecular Brain 2013 6:1.

\section{Submit your next manuscript to BioMed Central and take full advantage of:}

- Convenient online submission

- Thorough peer review

- No space constraints or color figure charges

- Immediate publication on acceptance

- Inclusion in PubMed, CAS, Scopus and Google Scholar

- Research which is freely available for redistribution 